\title{
Figuras do corpo e espaços do outro no cinema
}

\author{
Edson Pereira da Costa Júnior
}

Universidade de São Paulo, São Paulo, São Paulo, Brasil

\section{Resumo}

$\mathrm{O}$ artigo discute a representação do corpo em filmes de Philippe Grandrieux, João Pedro Rodrigues e Pedro Costa realizados na passagem da década de 1990 para os anos 2000. A partir da análise das dinâmicas visuais e da performance gestual, demonstra-se a existência de um programa comum baseado no primado das práticas sociais/afetivas sobre a natureza individual. A figura humana é condicionada a um princípio relacional: a mediação entre o eu e o outro determina os aspectos plásticos e a sensorialidade corporais, ao mesmo tempo que implica na produção de espaços capazes de acolher modos de convívio orientados pelo desejo e por regimes de partilha.

\section{Palavras-chave:}

Figura humana. Cinema contemporâneo europeu. Estética cinematográfica. Espaço. Exterioridade.

\section{Introdução}

Nos últimos anos, a crítica e a teoria de cinema destacaram as correspondências existentes em certos filmes realizados a partir $d a$ década de 1990 na Europa, Ásia e América Latina, especialmente a encenação realista de suas narrativas e/ou os dramas organizados em torno das sensações e das percepções corporais dos personagens. São resultantes do esforço hermenêutico por compreender as singularidades dessa produção fílmica matizada por traços transnacionais, por exemplo, as propostas conceituais associadas às definições de cinema háptico, estética do fluxo, realismo sensório e slow cinema. Não raramente, elas depositam sobre o corpo em cena um interesse particular, renovando um veio nos estudos de cinema que existe desde pelo menos a década de 1920, com os escritos de Balázs (2014) sobre a singularidade do "homem visível" ou, mais precisamente, do ser humano filmado.

A proposta deste artigo é circunscrever a problemática do corpo no cinema da virada da 
década de 1990 para os anos 2000 a partir de uma perspectiva diferente, embora complementar às mencionadas. Trata-se de discutir a articulação entre os regimes figurativos e as práticas afetivas/sociais a partir, primordialmente, da análise da plasticidade da imagem. Tal abordagem é em certa medida devedora do debate teórico realizado na França, nas décadas de 1980 e 1990, por pesquisadores que discutiram as formas visuais do cinema a partir da noção de "figura". Os casos mais significativos ou pelo menos mais conhecidos são os de Aumont (1996, 1998), Brenez (1998), Dubois $(1998,1999)$ e Vancheri (2011). Aqui, não traçaremos as nuances e tampouco o verniz que cada autor empresta ao debate, ora aproximando-se ora distanciando-se dos sentidos expostos por Auerbach (1997) para o termo. ${ }^{1}$ Neste trabalho, apenas convém lembrar que Aumont e Brenez tomam a ideia de "figura" para demarcar suas respectivas defesas da imagem cinematográfica enquanto meio capaz de refletir sobre o mundo independentemente da narrativa, da história contada pelo filme ou mesmo da submissão a um repertório exterior (cultural, histórico, ideológico etc.). Ao compreendê-la como figura, os dois autores conjecturam a existência de um trabalho formal realizado a partir da manipulação material e plástica. Dota-se, assim, a imagem de um poder de simbolização capaz de traduzir pensamentos. A dimensão de fatura, tácita na pintura e em outras artes plásticas, é enfatizada com o objetivo de afastar o cinema do automatismo técnico e, por conseguinte, da qualidade de reprodução ou mera cópia do referente real. Em vez de compreender um filme como ilustração direta do mundo, investiga-se antes o movimento entre a coisa e a sua imagem, isto é, as relações de semelhança e dessemelhança, de conformidade ou ruptura, entre o referente e a forma plástica. Essa perspectiva figurativa não se enclausura no formalismo, mas resgata o real a partir, inicialmente, do material sensível da imagem. Somente depois busca auxílio em outras disciplinas. Distancia-se, portanto, do método comum às grandes teorias. ${ }^{2}$

O uso da expressão figura humana para lidar com a representação do corpo sinaliza o desejo de compreender o ator, ou pelo menos seu

1 Em sua obra Figuras, o filólogo alemão recompõe a história das aparições e dos significados da noção de figura, desde textos da Antiguidade latina até a Idade Média. No debate francês, o autor foi frequentemente convocado, em especial por Jacques Aumont, Nicole Brenez e Philippe Dubois. Fora da França, Adrian Martin (2012) dedicou um livro ao tema.

2 David Bordwell (2005), entre outros pesquisadores alinhados à corrente cognitivista, identificam na pesquisa acadêmica, em especial na década de 1970, a prática de fazer dos filmes meros exemplos de teorias mais gerais sobre o sujeito e a sociedade. A análise fílmica prescinde da articulação de uma questão ou de um problema criado pelas obras para se pautar na aplicação de uma teoria, em especial a partir de ferramentas advindas da semiótica, do estruturalismo, do pós-estruturalismo, da psicanálise lacaniana e do marxismo althusseriano. 
corpo, como matéria visual modulável mais do que propriamente se dirigir à análise estética dos modos de interpretação - método que no Brasil tem recebido atenção nos últimos anos a partir de pesquisas como a de Guimarães (2019). Tal perspectiva enfatiza o corpo em sua passagem para a imagem, compreendendo que a silhueta, os personagens, a efígie, o corpo, a figura e o fundo se colocam em circulação constante. Conforme sinaliza Brenez (1998), se no real existe uma equivalência entre corpo, indivíduo e pessoa, o cinema burla tal lógica: a silhueta pode não fornecer um corpo, uma figura pode se distribuir em vários personagens, um personagem pode existir sem pessoa, um corpo, sem suporte, e assim por diante.

Partindo dos parâmetros sumariamente apresentados, discutiremos a representação dos corpos em expoentes do cinema contemporâneo, precisamente em cenas de filmes de Philippe Grandrieux, João Pedro Rodrigues e Pedro Costa, realizados no intervalo entre 1997 e 2006. A despeito da heterogeneidade de suas filmografias ou mesmo das condições históricas e sociais que marcaram seus modos de produção e recepção, na esfera do estilo seus filmes compartilham traços transnacionais. O principal deles talvez seja a apresentação da figura humana em narrativas delgadas, rarefeitas, geralmente compostas por planos de longa duração, com tramas organizadas à porfia da lógica causal. Pouco se sabe a respeito das personagens e de seus matizes psicológicos, pois em lugar de informá-los ao espectador a partir da transparência da mise en scène, da narração em off, ou mesmo dos diálogos, privilegia-se a performance gestual e/ou as dinâmicas da imagem. A exceção são os filmes de Costa, cuja palavra tem lugar nuclear.

Considerada a dificuldade de se compreender o sentido do corpo a partir de um personagem com comportamentos justificados pela lógica dramática, enfocaremos as propriedades figurativas, o discurso enformado pela dimensão sensível/visível. Mediaremos a investigação a partir de duas diretrizes: a busca por um repertório iconográfico e textual a respeito dos motivos analisados; e a análise do que se inscreve na superfície da obra, na figuração, e pode ser pensado pelo sentido e pela dinâmica que uma figura desempenha no interior do filme (DUBOIs, 1998). Recorrer a esses parâmetros auxilia a desbastar dos filmes o princípio que orienta e dá significado ao corpo representado. A hipótese a ser defendida nas próximas páginas é a de uma articulação entre a presença da figura humana e a relação com o outro, mediada por diferentes espaços: o da matéria da imagem, o do mundo figurado, e o espaço fílmico. A dinâmica relacional - ou a lida com o diferente - nos filmes de Grandrieux, Rodrigues e Costa, está emaranhada, 
respectivamente, à investigação da plasticidade cinematográfica, às manifestações do desejo e à formação de laços comunitários.

\section{Noite, espaço de travessia: a fratura entre corpos}

Vamos começar por Sombra (Sombre, 1998), do francês Philippe Grandrieux. O realizador se formou no Institut National Supérieur des Arts du Spectacle (INSAS), na Bélgica, e iniciou sua trajetória a partir de documentários e filmes para TV, além de instalações. Sombra é tanto o primeiro longa-metragem como também a obra que marca o início de um programa formal dedicado às experiências sensoriais evocadas a partir da expressividade pictórica e cinemática das imagens. O eixo da trama concentra-se nos assassinatos cometidos por um serial killer, Jean, durante as viagens que realiza pelo interior da França. A composição visual do filme, ostensivamente túrbida, enegrecida pelo pouco contraste das cores e pela subexposição constante, relega o personagem à figuração na forma de sombra.

A primeira aparição de Jean anuncia desde então o estigma descrito. Em plano médio, divisa-se o seu rosto com muita dificuldade num quarto escuro. Sem uma luz pontual que dramatize e evidencie algo no espaço, ou mesmo uma difusa que revele uniformemente o conjunto da composição, o que se tem é a refletância mínima na epiderme do corpo e na superfície do espaço e dos objetos, que aparecem no limite da visibilidade. Com roupa escura, o personagem facilmente se converte em silhueta negra que mimetiza a negrura do quarto. Em contraste, no mesmo aposento identificamos outra presença, a de sua vítima: uma mulher despida, cuja brancura da pele e a opulência das carnes - tal como uma figura feminina de Rubens - acabam se tornando um ponto de referência no espaço. Enquanto ela se impõe pela carnalidade, Jean parece se diluir, incorporando-se não mais ao espaço do mundo figurado, mas à superfície da imagem, ficando a meio caminho entre a presença no universo diegético e a existência enquanto ser de outra ordem.

A desigualdade da representação dos corpos masculino e feminino irá se repetir nos demais assassinatos, demarcando uma clivagem figurativa, uma cisão entre gêneros exposta pela plasticidade da imagem. De um lado, a vítima tem o rosto geralmente oculto pelos cabelos, pelo desfoque, pelo enquadramento e pela escuridão. A face, que poderia lhe conferir uma identidade, é confiscada. Sua figura somente existe pela exposição do corpo enquanto carnalidade e massa que serão ora exploradas pelo toque brusco e reticente de Jean, ora pela câmera que passeia pelas formas femininas com uma tal proximidade que dificulta a precisão dos contornos visuais em benefício de uma aparente tatilidade. De 
outro lado, Jean é apresentado inicialmente pelo rosto e pelo olhar. Quando não, se faz presente visualmente como sombra. A mesma lógica se repete no segundo assassinato, só que desta vez o que suprime a identidade da mulher são os olhos vendados. A notoriedade do seu corpo nu fica a cargo de uma luz que entra pela janela e se espalha pela cama sobre a qual está deitada. Jean aparece em contraluz, como silhueta, novamente em disparidade com o peso carnal da mulher.

Sabemos que, pelo menos desde a Antiguidade clássica, a cultura ocidental conferiu ao rosto e à voz não só um dos critérios de diferenciação entre o ser humano e os demais animais, mas igualmente o meio privilegiado de relação entre os indivíduos - e ainda de ascensão à ordem do inteligível por meio da beleza (FRONTISI-DUCROUX, 2012). Jean é o protagonista, então talvez seja natural lhe conceder um rosto, mas por que relegar às vítimas exclusivamente o corpo? Uma pista advém da parcial isomorfia visual entre as duas sequências. Em ambas, o protagonista não consuma o ato sexual e, antes de assassinar as mulheres, repete o gesto de colocá-las de pernas abertas, de frente para si, enquanto as contempla. A composição é a mesma: Jean em primeiro plano, de costas, na forma de silhueta, com a cabeça e parte do corpo a obstruir a visão do sexo das mulheres, situadas ao fundo. Tanto a disposição das figuras como a forte contraposição entre o protagonista, reduzido à forma de sombra impotente, e as mulheres, em toda a sua receptividade e presença corporal, separam Jean das vítimas, relegando-o a um espaço à parte que lhe nega a consumação do ato sexual e lhe reserva à escopofilia, como se uma tela se interpusesse entre o sujeito e o objeto do olhar e do desejo - talvez não por acaso o protagonista conhece a segunda vítima num peep show. A desigualdade de figuração entre os corpos masculinos e femininos corrobora uma clivagem entre gêneros, apresentados respectivamente como sombra e carne, que convém analisar.

As aparições da figura feminina ao longo de Sombra restringem-se, quase inteiramente, ${ }^{3}$ a apresentar o aspecto carnal, aproximando-se de uma representação da mulher costumeira na arte europeia do final do século XIX. A respeito do tema, Garb (1998) investiga obras de Edgar Degas e Jean Renoir que deslocaram a tradição do nu feminino como vetor de uma beleza ideal e desencarnada, por vezes transcendente, para uma espécie de potência sensual. Na análise de Torse de jeunne fille au soleil (1875, de Renoir), a autora observa que 
o tratamento da mulher nua na paisagem idílica é associado à tentativa de deslindar parcialmente seu corpo de signos e de artifícios da civilização, promovendo o retorno a uma feminilidade pré-moderna, "natural" - ainda que, ironicamente, corresponda a uma concepção de natureza e de feminino marcadamente cultural. A presença social da figura é acentuada pelo aspecto tátil dado ao seu corpo, com o modulado constituído pelo rebatimento entre a carne e a dança fervilhante das cores e das luzes. Acentua-se sua existência em meio às vicissitudes do espaço, ao agora de sua natureza carnal.

A representação do nu feminino em determinados pintores de meados do século XIX, assim como no filme de Grandrieux, acaba por reproduzir e manter-se em consonância com um discurso e uma figuração da mulher comumente identificados pela teoria feminista. Trata-se da tendência a representar o corpo carnal como sendo unicamente o feminino, vinculando as mulheres à matéria (seja ela inerte, morta, fecunda, imoral ou procriadora), enquanto ao homem é reservada a posição daquele que assume o domínio racional. ${ }^{4}$

Se não podemos atribuir a Jean o viés da razão, é verdade que as mulheres são figuradas por uma dificuldade de agenciamento de sua forma, por um excesso da matéria corporal. Nuas ou vestidas em trajes sensuais, como no caso das dançarinas que Jean encontra numa casa noturna, elas aparecem na imagem pela perda dos contornos figurativos, seja pelo desfoque, pelo excesso de movimento das atrizes, pelos jogos de luzes coloridas que sobre elas se projetam ou pela montagem de planos acelerada, que fragmenta as figuras. A mise en scène de Sombra forja a dificuldade de plasmar o feminino, de dar-lhe uma forma visual estável, de agenciar sua presença de modo assimilável e claro no espaço inteligível. A esse excesso, temos Jean como instância que tenta lidar e controlar o corpo da mulher. Sua incapacidade frente à materialidade carnal das vítimas, o fracasso em usufruir do desejo e consumar o ato sexual, converte, a partir dos assassinatos, a pulsão libidinal em pulsão de morte.

4 A referência aqui é ao artigo em que Spelman (1982) discute, a partir de Platão, como a valorização do corpo em detrimento da alma, bem como a primazia do racional sobre o irracional, frequentemente ecoa uma distinção de gêneros. 0 homem é associado, ou está mais próximo de ascender, às faculdades mentais e ao domínio da alma, enquanto a mulher é alinhada ao lado físico e corporal da existência. A autora ainda identifica e debate os reflexos da distinção entre alma/razão e corpo/irracional em teóricas feministas, como Simone de Beauvoir, Betty Friedan e Shulamith Firestone. Encontramos o artigo a partir de uma citação feita por Butler (2009), que associa Spelman a uma tradição feminista crítica ao binarismo mencionado, diferente da de autoras como Luce Irigaray, que propõe uma leitura da história do feminino na filosofia ocidental sob outros parâmetros. 
A figuração de Jean na forma de sombra e, em consequência, sua constante integração à superfície da imagem cinematográfica, ganha um sentido a mais quando a relacionamos com a ideia de uma presença feminina a ser reiteradamente coagida posto que difícil de ser enformada. Ecoando um dos usos da sombra na literatura, em obras como A Divina Comédia, de Dante Alighieri, em que funciona como sinal da ausência ou perda parcial do corpo (BELTING, 2004; STOICHITA, 2016), o percurso de Jean se assemelha a uma peregrinação a fim de prover-se da matéria carnal (feminina) que lhe falta. Há uma natureza vampiresca nessa busca de uma figura umbrática pelo seu insumo, o que talvez remeta a um diretor influente para Grandrieux, F. W. Murnau, notadamente o tratamento visual que confere à criatura monstruosa de Nosferatu (Nosferatu, Eine Symphonie des Grauens, 1922): uma sombra que perambula em busca de alimento no corpo feminino. A analogia não implica em tomar Jean por uma criatura fantástica e sem corporeidade, mas em reconhecer que ao longo do filme são empregadas estratégias figurativas que sinalizam uma espécie de debilidade, de perda de substancialidade de Jean, reforçada pela contraposição entre o tratamento plástico dado aos diferentes gêneros.
Sombra se desenrolaria sob o signo da disjunção entre os corpos masculino e feminino? Provavelmente não. A hipótese aqui é a de que as rupturas figurativas, das quais as principais são entre sombra e carne, sujeito e objeto do olhar, são compensadas, ou senão minimizadas, pelo espaço pictórico preto que enubla e se projeta sobre o campo visual. Por meio dele seria forjada a travessia irrealizável, fazendo da sombra (espacial) meio, ${ }^{5}$ território favorável a um tipo de comunicação, à troca das sensações que emanam dos corpos, mesmo que isso se dê de modo não consensual.

Como outros filmes de Grandrieux, Sombra cria pelo negrume da imagem efeito similar ao de um dispositivo desenvolvido no início e consolidado ao final do século XIX, a partir da tela preta e dos black theaters: a escuridão artificial. Presente em fantasmagorias e outros espetáculos de magia, cinema, teatro, fotografias amadoras e profissionais, seu arranjo básico dependia do jogo entre visibilidade e invisibilidade, da oposição visual entre os elementos revestidos de preto, mimetizados ao fundo de mesma cor, e os postos em evidência por tecidos brancos ou pela iluminação. Em alguns espetáculos teatrais, atores com roupas escuras ficavam ocultos pela tela preta, o que permitia manipular objetos 
do palco como se estes se movessem sozinhos. Pelo mesmo artifício, forjavam o desmembramento de partes do corpo, incluindo a decapitação. $\mathrm{O}$ cinema de Georges Méliès herdou essa técnica, e a incrementou junto à famosa "parada da câmera" e à sobreposição de fotogramas, fazendo com que a escuridão artificial se tornasse um espaço intersticial onde tudo era possível ao corpo, inclusive transgredir as leis que regem vida e morte (ELCOTT, 2016).

A qualidade do preto - seja o da escuridão artificial, seja o da noite - enquanto um espaço de travessias se aproxima de certos motivos da pintura ocidental europeia, em que funciona como meio para estreitar a distância entre duas formas de vida. Pensamos, em particular, na obra de Caravaggio, cujas telas não cessam de promover o cruzamento entre polaridades, em especial os domínios do sagrado e profano, do realismo e do idealismo. Uma das estratégias do pintor era efetuar a criação de uma zona de permeabilidade em seus quadros, pelo uso da escuridão (MILNER, 2005).

Como dito anteriormente, não há escuridão artificial em Grandrieux. Contudo, atribui-se à noite e ao negrume espacial um efeito similar. Em Sombra, como em outros filmes do realizador, o espaço ensombrado absorve o que está em campo. A imagem é ligeiramente enturvecida. Graças a isso, a figura e o fundo estão em vias de tornarem-se um só, de uma comunhão total, levando adiante o potencial da noite como meio de indistinção entre os seres (BANU, 2005). Ao encobrir a visibilidade mesmo que parcialmente a partir do negrume, o efeito inicial é o esboroamento das fronteiras espaciais, dos limites físicos, mas também dos contornos que delineiam os corpos e os separam do contexto em que se encontram. A figura humana pode tanto mergulhar como também emergir do preto, deslocando-se dentro de um campo escuro cuja opacidade demarca uma zona diferenciada.

Para além dos efeitos sobre o espaço físico, o preto sinaliza a entrada no universo das sensações corporais. Em Sombra, os momentos de maior integração das figuras com espaço ensombrado são os de experiências limites, extremas, violentas: nas cenas de embate físico ou de parcial envolvimento sexual entre Jean e suas vítimas. Nesses instantes, sob o véu da escuridão, a câmera se aproxima das figuras até o desfoque dos corpos. Os procedimentos sublinham a superfície ou mesmo a matéria da imagem (AUMONT, 2009), uma vez que convertem o espaço profundo e representado em espaço "achatado", abstrato, não representativo/não figurativo, em razão do afastamento ou da perda da referência imediata do mundo real. O privilégio que seria concedido ao olhar do espectador a partir da disposição perspectivada e organizada dos 
elementos visuais no campo é substituído pela imagem como camada não diferenciada de signos plásticos (formas desfocadas em movimento num fundo preto). Assim, apresenta-se ou se sugere o universo tátil experimentado pelos personagens nas cenas de violência e de estados de excitação sensorial.

São comuns nos instantes de violência os ruídos de respiração dos personagens, os gemidos de sofrimento das mulheres agredidas e o estrido do embate físico. Na imagem, contudo, é difícil ancorar tais indícios sonoros em uma forma precisa. A presença da figura humana acontece pela dispersão no campo de tudo o que a ela é relativo, contaminando o filme com sua existência fracionada, evocada pelas sensações dos personagens. O preto pictórico tensiona a imagem até o seu limite. As experiências limiares não podem ser modeladas dentro de uma forma plástica precisa, reforçando a impossibilidade de uma plena associação, pelo grau de analogia visual, entre a imagem cinematográfica e o fenômeno sensório. Afinal, poder-se-ia indagar: como fazer uma representação visível do que tem natureza imaterial e intensidade não agenciável o universo extático das sensações corporais?

Vale frisar, ainda, que a mudança do espaço representativo para o espaço preto também interfere nas bordas do quadro cinematográfico. Na escuridão, tem-se como efeito a diluição dos limites entre a tela e a sala de cinema, fazendo do preto uma zona de continuidade entre o universo diegético e o público. Reconfigura-se a função que Aumont (1989) estipulava para a escuridão do dispositivo cinematográfico: a de quadro-objeto que deveria fazer da imagem um objeto separado do mundo. Em lugar disso, o preto é o tecido de cerzidura entre a diegese e o real, ampliando a imersão criada pela câmera, em sua excessiva proximidade dos corpos. Criam-se condições que favoreçam ao espectador a percepção de estar participando do que está diante da tela, e não apenas observando.

Com a baixa luminosidade da imagem e a pouca definição dos limites figurativos, os corpos representados em Sombra se dissolvem num mesmo espaço, como se ali, na matéria da imagem, pudesse se realizar um tipo de correspondência entre Jean e as mulheres, entre o masculino e o feminino. Supomos que a integração da figura humana com o campo escuro responde a uma lógica da circularidade. A escuridão é o espaço da virtualidade, o lugar privilegiado para abrigar a relação entre os seres. A comunicação até então impossível no âmbito das relações entre os personagens, dada a violenta chave de misoginia pela qual o outro é uma ameaça ou uma vítima, é esboçada pela imagem convertida em antro das sensações, única forma de negociação e sociabilidade da figura humana. 
O negrume pictórico exime os corpos de uma comunhão ou igualdade pautada no consenso, na negociação e no afeto. Modos de conciliação sociais são preteridos em benefício de uma troca que só se revela pela ameaça à integridade física. O desejo de uma horizontalidade acontece na perda dos contornos figurativos do corpo, pela redução das diferenças, sejam elas relativas à aparência, ao gênero ou à natureza, a fim de um nivelamento pela intensidade da experiência física que reverbera na plasticidade preta da imagem.

\section{Espaço do mundo, palco dos desejos: um corpo busca outro}

Se em Sombra, de Grandrieux, chamamos a atenção para a constante fratura entre masculino e feminino, cuja violenta relação reverbera e tenta ser compensada na matéria da imagem, transformada em superfície (preta) de trocas, agora gostaríamos de atentar para uma filmografia que se desenrola sobre a constante procura de um corpo por outro. Adeus, Dragon Inn (Bu San, 2003), de Tsai Ming-liang; e O fantasma (2000), de João Pedro Rodrigues operam nessa chave. Aqui restringiremos a análise ao segundo, filme de estreia de Rodrigues, cineasta português que ao longo da filmografia trabalhou, entre outros temas, com as metamorfoses e os travestismos corporais associados ao universo queer, mas também à iconografia cristã e à história de Portugal.
O fantasma enfoca a rotina de um gari de Lisboa, Sérgio, e seu impulso sexual por um rapaz que conhece durante um turno de serviço. O que poderia constituir mera atração ou paixão, desenrola-se de modo abrupto e intempestivo. O personagem passa a espionar o homem desejado e a visitar os endereços que frequenta. Sua obstinação, que beira a obsessão, permeia também o universo dos objetos. Sérgio irá procurar, guardar e interagir com peças de roupa, uma motocicleta e o que mais pertencer ao rapaz. Ao longo das investidas por lugares e objetos, encontrará parceiros para relações sexuais casuais que, deve-se sublinhar, em nada refreiam o seu desejo sexual.

Comparado ao filme de Grandrieux, O fantasma optará predominantemente por uma mise en scène que investe em espaços perspectivados, com ampla profundidade de campo. A ênfase é dada ao mundo representado, mais do que propriamente ao espaço plástico ou à materialidade da imagem. A figura humana é com frequência situada em interiores ou espaços abertos a partir de planos médios e planos gerais, feitos com câmera fixa. Os poucos travellings restringem-se a acompanhar o deslocamento do corpo no espaço. Dessa maneira, a proeminência é do gesto - entendido como ação física.

A primeira observação sobre o filme de Rodrigues é a potencialização da figura 
humana a partir da ênfase dada à pele e ao toque como meios de expansão do corpo (SEIJA-VERGEZ, 2005). Tudo começa durante um turno de serviço, quando revira a lixeira da casa do rapaz que deseja. Ali encontra uma sunga puída e rasgada. Examina-a. Cheira-a repetidamente, supostamente experimentando ou fantasiando pelo olfato a presença do outro. Guarda consigo a peça e em outro momento a veste: reparando no corte, olhando para o espelho em diferentes posições, apalpando-se para perceber o volume do corpo, reparando em como a carne é modelada, sugerindo ao espectador a experiência do toque.

O capítulo mais emblemático da mediação com o outro por meio da pele acontece quando Sergio visita a mesma piscina pública onde havia visto o seu objeto de desejo. Ali, em outro momento, observou o rapaz nadar e, depois, no vestiário, trocaram olhares. À noite, o protagonista invade o prédio da piscina para visitar os mesmos lugares em que o viu. Mas como o paradigma de O fantasma não é o de acessar a realidade sensível pelo olhar, Sergio precisa ir além da mera observação dos espaços: ele se despe e mergulha na piscina. $\mathrm{Na}$ água, encontra uma posição confortável, flutua, e retira a sunga, que passa a ser desnecessária à medida que o próprio meio se converte na presença do outro, cujo acesso se dá pela pele. Para isso, despir-se, liberando a superfície corporal das contenções sensoriais impostas pela cobertura da roupa é o primeiro passo. O segundo é a disposição física: com braços e pernas abertos o personagem tanto se põe à disposição do olhar espectatorial como reforça uma total sujeição do corpo ao mundo. Um mundo particular e afetivo, o do outro.

A cena da piscina revela o contato entre um corpo presente e outro ausente a partir de um medium partilhado a despeito da decalagem temporal. A figura humana sonda o entorno, friccionando o corpo contra a raia, experimentando a água, estabelecendo uma contiguidade tátil com o que a envolve. Isso culmina, visualmente, numa espécie de integração. A figura é apresentada enquanto matéria articulada, parte do ambiente. A sua pele é imantada à superfície espacial, à pele do mundo. A cena leva a um nível forte esse enraizamento de Sérgio no espaço físico, concreto, criando um mutualismo tátil entre corpo e meio.

Imiscuir-se ou engajar-se ao espaço é uma demanda interna do próprio filme de Rodrigues, no qual a presença e o modo de conhecimento da figura humana pertencem à ordem da sensação. Ao incumbir a pele da função de mediadora, passa a ser determinante a dimensão tátil. Para que algo afete os personagens e mesmo para que eles existam no 
filme, é necessário que em algum momento estabeleçam uma relação baseada no toque, como se fosse preciso sondar e confirmar a existência sólida de toda figura e objeto no espaço. Em razão disso, a economia figurativa é pautada na proximidade. Diferentemente da visão, capaz de perscrutar pela distância, o toque exige uma prospecção pela cercania, estar rente e diretamente, epidermicamente, envolvido com o seu objeto. No mesmo sentido, o contato físico, mesmo quando apreendido visualmente é associado à ideia de um universo posto em relevo, transformado em matéria. O tipo de presença tátil guarda uma segunda singularidade diferente daquela propiciada pela visão: estar ou não estar visível já não é sinônimo de ocupar um ambiente, como se vê na visita que Sergio faz aos lugares antes frequentados pelo rapaz que deseja.

A pele parece se tornar no filme o órgão responsável por mediar a relação com o universo objetal e espacial, mas também um atributo que impele e justifica a pequena jornada de Sergio à piscina e aos demais espaços da lembrança. Ela é dotada de uma pregnância e durabilidade das percepções e sensações, fazendo perdurar o que inicialmente seria efêmero, estendendo a permanência de um corpo numa temporalidade indefinida ou em todo caso mais longa do que aquela restrita à presença física, numa memória e numa espacialização da sensação.
O fantasma talvez participe do que Elsaesser (2015, p. 42) sublinha a respeito da crise da cultura visual no que considera ser um "cinema mundial" contemporâneo pós-epistemológico, marcado pela reorientação da episteme de representação do conhecimento como visionamento para "uma renovação de interesse e reinvestimento no 'corpo', 'nos sentidos', pele, tato, toque e na dimensão háptica, ao qual corresponde na filosofia e na neurociência evolucionária à ideia da 'mente personificada". O autor ainda distingue o legado do projeto construtivista dos estudos culturais de atribuir menos ênfase aos "limites de determinações sociais ou posicionamentos dos sujeitos e, em vez disso, concentrar nos espaços de apropriação positiva, no 'jogar' e especificamente na 'performatividade"'. (p. 43). Mantém correspondência com esse último comentário a proposição discutida por Baltar $(2012,2015)$ sobre a pedagogia das sensações/dos desejos. A autora usa o termo para se referir ao cinema queer lésbico produzido a partir dos anos 2010, em que o peso dos conflitos socioculturais na ação dramática é reduzido. Em seu lugar, privilegiam-se as relações homoafetivas a partir das dimensões do desejo, do cotidiano e da intimidade, evocadas pelos efeitos visuais e por uma narrativa que mergulha nas trocas afetivas dos corpos em cena, fazendo destas um meio de partilha e experiência com o espectador. Embora O fantasma esteja fora da circunscrição fílmica e temática 
demarcada por Baltar (2015), o filme também põe em relevo as jornadas de prazer de Sergio em detrimento de uma possível abordagem social e cultural, na esfera do drama, sobre a homossexualidade do protagonista. Também fica de fora da diegese uma complexificação das relações de classe, que poderiam vir à tona pela profissão do protagonista. Trata-se de um cinema dedicado à exploração dos sentidos e também à performatividade do corpo.

Se o filme de Grandrieux levava para a superfície da imagem a sexualidade conturbada entre os personagens, O fantasma também encontrará modos particulares de apresentar os efeitos do desejo sobre a figura humana. Aqui, enfocaremos apenas um: a economia libidinal. O filme de Rodrigues forja um regime figurativo em que o desejo sexual subverte a ordem dada pelo drama e pelos papeis sociais da figura humana, anunciando um mundo subterrâneo, um duplo do primeiro, sua inversão ou seu desvio.

Uma cena banal de O fantasma dá os contornos do que se descreve. Nela, Sérgio e sua amiga Fátima estão no intervalo de trabalho. Ela dirige um pequeno carro enquanto ele está na carroceria. Não estão indo para nenhum lugar. É apenas mais uma sequência, como tantas outras do filme, de dispêndio de energia: o automóvel vai e vem pelo espaço descrevendo uma trajetória sinuosa, enquanto Sérgio grita para que ela acelere mais. Simples brincadeira de adolescentes? Ali aparentemente se engendra um processo de contaminação entre matérias (o automóvel e a figura humana) que continua na próxima cena, com Sérgio e Fátima brincando com um objeto fálico, pressionando-o contra a base do abdômen. Ele inicia o jogo. Posteriormente, ela toma a peça para si e tenta fazer o mesmo movimento. Ao fim, ele se senta atrás dela e a ajuda a manipular o objeto contra o corpo, numa frequência rítmica cada vez mais intensa. O ruído provocado pelo material sugere o atrito de dois corpos transando. Ora, em um filme que a todo momento evoca o sexo, a cena, com a presença fálica do objeto, a posição e o gesto conjunto do casal, é mais do que suficiente para insinuar que um jogo inocente é progressivamente impregnado pela libido. A suspeita não nos parece temerária e nem pode ser descartada, uma vez que logo após a brincadeira, os dois vão para o chão, Sérgio lambe o rosto de Fátima e a ação termina em sexo. No próximo plano, os dois aparecem no quarto dele na manhã do dia seguinte, vestindo-se. As imagens da transa, a única heterossexual do filme, são omitidas pela elipse - a elisão reafirma o que já deve estar claro para o espectador: o interesse de O fantasma é pelas relações homoafetivas e pelos corpos masculinos. 
O ziguezague do carro no início da sequência sinaliza, cremos, a existência de uma energia cuja modulação envolve conjuntamente o corpo das figuras e o automóvel, as matérias orgânica e inorgânica. A cena seguinte, com o objeto fálico, dá prosseguimento a essa espécie de comunicação entre os seres, independentemente de suas respectivas ontologias. Efetivamente, não se trata de total simetria. Em todo caso, apesar da constituição díspar de uma e de outra espécie, elas acolhem e partilham de um mesmo fluxo. Trata-se de algo reincidente em O fantasma: objetos e espaços são contaminados pela pulsão sexual dos corpos. Isso pode ser observado nas cenas que: a) Sérgio toma banho com uma ducha e usa o objeto para interromper o fluxo de sangue e impulsionar a ereção; b) faz carícias numa motocicleta como se estivesse diante de um corpo humano; c) lambe as paredes de um banheiro e toma banho nas mesmas águas que o homem desejado para tentar prolongar sua presença sensual. Espaços e objetos também são tratados como se suas propriedades fossem parcialmente itinerantes: já não podem ser definidos em si mesmos; derivam, sim, do que o desejo, encarnado pelo gesto, consegue deles extrair. Guardam uma funcionalidade virtual, mas passível de ser concretizada.

A sequência que inicia com o carro e termina com o sexo evidencia traços de uma economia libidinal ${ }^{6}$ capaz de atravessar e contaminar indistintamente figuras, objetos e espaços, convertendo-os em vetores pelos quais a pulsão de um corpo é capaz de ser transmitida de um ser ou de um reino a outro. Independentemente das respectivas ontologias, de animados ou não, os seres se tornam instrumentos de vazão ou de usufruto do desejo sexual dos personagens. Como o que discutimos a respeito da pele, elemento capaz de colmatar o abismo que separa Sergio do rapaz que o atrai, O fantasma lida com uma constante expansão da corporeidade da figura humana, criando uma circularidade junto aos seres, objetos e espaços com os quais interage.

\section{0 espaço fílmico como arquitetura da comunidade: 0 corpo coletivo}

O terceiro caso que analisaremos é o do cineasta português Pedro Costa. Longe de uma representação da figura humana a partir dos desejos, das relações sexuais e do

6 Para além das cenas descritas, o uso da expressão "economia libidinal" leva em consideração como a trama é modelada a partir do desejo de Sérgio. Do início ao fim de 0 fantasma, o itinerário do protagonista é organizado a partir de encontros com parceiros sexuais, reverberações da sexualidade no cotidiano e, sobretudo, conversão das situações dramáticas, dos espaços e dos objetos em palco do desejo. A libido, portanto, mais do que uma força subreptícia a emergir esporadicamente, é o eixo estruturante, a lei que preside e conforma a narrativa. 
engajamento sensorial, tal como se viu até aqui em Grandrieux e Rodrigues, a estética austera de Costa está mais próxima de um realismo social (NOCHLIN, 1984), da tentativa de procurar recursos estéticos para recuperar, no âmbito da obra, as condições materiais daqueles que filma. Analisaremos cenas da chamada Trilogia das Fontainhas: Ossos (1997), No quarto da Vanda (2000) e Juventude em marcha (2006). Nessa trinca, acompanha-se a vida de imigrantes cabo-verdianos e demais moradores da favela das Fontainhas, em Lisboa. Juntamente à miséria social em que vivem, os filmes apresentam os gestos de solidariedade, a irmandade que se cria nos encontros e na convivência entre vizinhos. A partir de No quarto da Vanda, tal tessitura social é ameaçada pela destruição da favela, em razão de uma ordem da Câmara de Lisboa. Os moradores serão remanejados para um conjunto habitacional no bairro social Casal da Boba, processo de transferência que se conclui em Juventude em Marcha. De um filme a outro, sobretudo nos dois últimos, a demolição espacial ameaça fraturar a experiência comunitária. Os moradores serão separados do território que preserva suas memórias pessoais e sociais. Precipita-se uma atomização do corpo coletivo, uma vez que nem todos aceitam a mudança, preferindo procurar outro lugar para morar. É neste cenário de vulnerabilidade que o cinema de Costa participa da cerzidura e expõe os meandros constituintes dos laços comunitários.?

Se Sombra faz ressoar nas propriedades da imagem o fracasso da relação entre masculino e feminino, e O fantasma transforma a corporeidade da figura humana, os objetos e os espaços a partir do desejo sexual, o princípio relacional existente em Costa mobiliza vias de acesso entre os moradores do bairro das Fontainhas e faz do espaço fílmico (ROHMER, $2000)^{8}$ o lugar de solidariedade dos corpos, mas também de resistência em face da miséria em que vivem.

7 Na trilogia, ocorre uma mudança entre o primeiro filme e os dois últimos, envolvendo tanto o modo de produção como o resultado final. Enquanto Ossos é alicerçado sobre um roteiro e se desenrola por uma decupagem em certa medida "transparente", priorizando a narração de determinados eventos a partir da ação dramática dos personagens, No quarto da Vanda e Juventude em marcha recorrem a estratégias, comuns em documentário, que potencializam os "efeitos de real" (BARTHES, 1968), ou talvez os "riscos do real" (COMOLLI, 2008), isto é, a aproximação a uma dada realidade histórico-social a partir do que escapa ao ordenamento de estruturas narrativas convencionais. São escolhas que coincidem com a redução da equipe de filmagem e do aparato cinematográfico, permitindo uma maior intimidade entre o realizador e as pessoas que filma. Dito isso, para nosso objetivo consideramos questão secundária a diferenciação entre as inflexões ficcional e documental na trilogia.

8 Para Rohmer (2000), é o espaço virtual reconstituído pelo espectador a partir do reagrupamento que faz dos fragmentos de um filme. Espaço, portanto, dinâmico, e não estático, uma vez que sua elaboração leva em consideração o movimento: 1. dos motivos filmados, e 2. do aparelho, pelo deslocamento da câmera ou pela sucessão de planos a partir da montagem. 
A figuração de um corpo coletivo na Trilogia das Fontainhas depende, inicialmente, de uma lógica vetorial. Cria-se um elemento que irá transitar entre os personagens estreitando a distância que preservavam entre si, implicando-os numa existência coletiva, alinhavando-os em torno de um objeto ou destino comum. Comecemos por Ossos. O filme se constrói em torno de um casal de adolescentes que acaba de ter o primeiro filho. Mergulhados na pobreza e sem meios de subsistência, os pais sofrem o abalo do recém-nascido indesejado. A mãe tenta se matar. O pai segue com a criança no braço para pedir esmola no centro de Lisboa. Nesse filme, quem assume o desígnio de vetor é o bebê. Corpo vivo, mas cuja existência paira sobre o casal de adolescentes como um espectro de morte, marca maldita a disparar a pulsão de destruição, será ele a criar um intra-espaço, um meio comum a ser partilhado pelos personagens. O bebê passa de mão em mão. Conecta, estreita e expõe a relação entre os moradores do bairro, assim como estabelece o contato dos pais com a enfermeira que, a partir de então, se sentirá eticamente impelida a ajudá-los, alimentando-os, tentando aconselhá-los ou tão somente dividindo o silêncio em entendimento.

No quarto da Vanda mostra o cotidiano dos habitantes das Fontainhas durante o processo de destruição do bairro pela prefeitura de Lisboa: desde os encontros solidários para conversar até as reuniões para utilizar crack e heroína. A droga se tornará o vetor a atravessar os corpos em cena e a estimular a criação de um espaço imaginário e ritualístico onde o território físico está em vias de ser destruído. O mais próximo do gesto coletivo é o envolvimento conjunto no preparo pormenorizado do crack e da heroína, bem como seu subsequente consumo. A injeção e o trago são os modos de criar um tecido conjuntivo. Ali surgem as conversas, as narrativas pelas quais a experiência e o imaginário dos indivíduos são sedimentados em memória coletiva, numa permanência, a princípio duradoura, contraposta à demolição iminente. A extensão de um corpo a outro é intrínseca ao que ameaça e nega a vida: o depauperamento das condições materiais pela pobreza e a agressão ao corpo pela droga. Por vezes, o consumo acontece às escuras ou sob a parca luz de velas. A escuridão dilui as figuras individuais na penumbra. Vestígios anatômicos e o som de vozes murmurando histórias transitam e ocupam o plano fantasmagoricamente. A integridade física desaparece em prol de uma permanência coletiva emoldurada pela horizontalidade visual da escuridão.

Juventude em marcha dá continuidade a No quarto da Vanda, mostrando a mudança dos antigos moradores das Fontainhas para o bairro Casal da Boba. No filme, a figura a assumir a lógica vetorial é o protagonista, 
Ventura. Ele vai, de um plano a outro, de rua em rua, de casa em casa, conversando com os vizinhos, a quem chama de filhos. Por meio das visitas, estabelece um liame, uma ligação que tem como centro sua existência. Os laços comunitários que em Ossos e em No quarto da Vanda existiam por um prisma preponderantemente negativo, um extermínio dos corpos por si mesmos e pela bruta realidade que os oprime, passam a ser forjados por um gesto vivente e agregador livre da pulsão destrutiva.

O vetor na Trilogia das Fontainhas é conformado por meio de corpos (o recém-nascido e Ventura), gestos (consumo da droga) e objetos (a droga). Deve-se acrescentar que sua operacionalidade depende da criação de figuras espaciais de passagem que facilitem a comunicabilidade pela redução dos muros reais e simbólicos. Dito de outra maneira, o trânsito dos vetores exige a criação de uma abertura, de uma brecha que permita violar as barreiras impostas pelas estratificações espaciais/sociais e, assim, transgredir o que poderia segregar e alienar a figura humana. O primeiro objeto a assumir tal função são as portas, abundante e quase obsessivamente espalhadas ao longo da Trilogia das Fontainhas. Em No quarto da Vanda, a chegada de Nhurro na casa de Vanda - filmada como uma espécie de invasão, dado que o visitante abre a porta por fora - mostra a detida atenção ao objeto. Não só pelo uso do plano detalhe, mas também porque depois de "violar" o bloqueio, a figura permanece na soleira da porta, nem dentro do quarto e nem fora dele. O mesmo "não lugar" será assumido em Juventude em Marcha por Ventura, quando visita uma de suas filhas. Ainda o personagem, no apartamento no Casal da Boba, abre e fecha, sucessiva e comicamente, uma das portas, como se a atestar sua funcionalidade. Por que tanto interesse? Depois de ser desalojado, Nhurro aparece carregando um saco com os seus poucos pertences e uma porta. Comum também são corpos no interior de imóveis, geralmente de um quarto, filmados a partir de um ponto de vista externo, pela fresta da porta entreaberta, enquadramento comum em Ossos.

Como o próprio realizador já admitiu, a porta não é para ele um objeto qualquer (COSTA, 2010). A fim de compreender o seu uso como mecanismo ambivalente e essencial para a criação de uma lógica de circularidade, é necessário pensá-la à luz do cinema fantástico - tão caro a Costa. Entre outros elementos daquele gênero que o realizador se apropria, está a porta como dispositivo fronteiriço de impedimento e comunicação entre mundos. Nos filmes das Fontainhas, ela é o entre dois, o que muitas vezes simboliza o limbo social dos moradores, o lugar de passagem, dada a iminência de perderem suas propriedades. Jean-Louis Leutrat comenta a função que a porta assume no cinema fantástico: 
Tematicamente, a porta, ela também uma fronteira, é ao mesmo tempo um lugar de passagem. Ela define, fecha, delimita o território. Relacionada à separação, ela funciona com a ponte, como percebe Georg Simmel. Ela está fechada pelo interior, a ponte abre em direção ao exterior. A ponte, como a porta, separa, mas também sutura: na versão da história de Dr. Jekyll proposta por Rouben Mamoulian, uma passarela transpõe o espaço que separa o laboratório do doutor do seu apartamento; a porta, como a ponte, abre, mas também enclausura: além da porta, como também além da ponte, encontra-se o país dos fantasmas (LEUTRAT, 1995, p. 62, tradução nossa) $)^{9}$.

A finalidade das portas em Costa está alinhada com a das janelas, que potencializam a permeabilidade entre o que acontece no espaço privado e no espaço público. Em Ossos, pelas ruelas do bairro, são vistas as famílias que estão em casa. Pelas casas, observa-se os passantes na rua. De todos os filmes, a arquitetura é talvez a mais evidente nesse aspecto, pois compartimenta o campo em um jogo de enquadramento e re-enquadramentos que criam vasos comunicantes. Pela janela: uma das vizinhas vê a chegada do bebê que tudo irá secretar no filme; Tina se intromete durante o sexo de Clotilde com o marido para pedir ajuda. Em Juventude, Ventura, da rua, fala com a "filha" que está dentro de casa. Em Vanda, Russo põe a mão na cozinha da casa de Vanda para perguntar se a mãe dela não quer comprar o passarinho que ele encontrou. As janelas reforçam as portas como elementos de infiltração, diluição ou flexibilização das fronteiras que deveriam separar os espaços e, consequentemente, os corpos.

A circularidade é desencadeada também por motivos pontuais que surgem em um corpo e reaparecem ou ganham continuidade em outro. Fora da trilogia, Casa de lava (1994) antecipa a prática quando o vestido vermelho que caracterizava a protagonista aparece em outra personagem do filme. Já em Juventude, há gestos que são retomados por diferentes figuras, como o das mãos sobre a cintura: primeiramente feito pelo segurança que retira Ventura do museu Gulbenkain. Posteriormente, o próprio Ventura o repete. Em No quarto da Vanda, a protagonista tenta procurar um isqueiro para ascender um cigarro de crack. Até encontrar um que funcione, joga dezenas deles numa lixeira. A montagem concatena a cena com o plano de uma mão mergulhada na treva a segurar um isqueiro aceso na casa de Nhurro, estabelecendo um raccord entre as

9 Thématiquement, la porte, elle aussi une frontière, est de même un lieu de passage. Elle définit, enclôt, délimite le territoire. Liée à la séparation, elle fonctionne avec le pont, comme le remarque Georg Simmel. Elle est refermée sur l'intérieur, le pont ouvre vers l'extérieur. Le pont comme la porte sépare, mais il relie : dans la version de l'histoire du Dr Jekyll proposée par Rouben Mamoulian, une passerelle enjambe l'espace qui sépare le laboratoire du docteur à son appartement ; la porte comme le pont ouvre, mais elle clôt : au delà du pont, c'est le pays des fantômes. 
diferentes moradias. Essa continuidade entre o quarto de Vanda e a sala de Nhurro acontece tanto no nível da experiência com a droga, como também pela ressonância e espelhamento gestuais.

A dinâmica circular ainda depende do som ao redor, da ausência de isolamento acústico das casas, de onde sempre se escuta o que se passa no exterior, impedindo a existência de um espaço eminentemente privado. Por fim, deve-se acrescentar os corredores do bairro das Fontainhas. Não raramente eles fazem a ligadura de uma casa a outra na montagem. Ao mesmo tempo, funcionam como espaço de passagem de Ventura quando visita os filhos, ou de Vanda quando vende verduras no bairro. Juntos, os elementos listados figuram um espaço partilhado, uma topografia do outro, rede de constante interação entre figuras e sons capaz de forjar um corpo coletivo onde poderia existir apenas as ruínas e a atomização dos indivíduos em torno de suas misérias pessoais.
Os vetores e as figuras de passagem nos filmes de Costa transformam o próprio espaço fílmico em um lugar do comum. Essa afirmação leva em consideração a arquitetura da favela das Fontainhas, permeada por vasos comunicantes (janelas, corredores, portas e ruídos) que conectam o privado ao público, mas também a ênfase que esses elementos recebem da encenação, constituindo-se motivos estruturantes dos filmes. No mesmo sentido, consideramos a circularidade estabelecida na contingencialidade dos encontros e das travessias: pelas visitas de vizinhos, pelas partilhas (das conversas, da solidariedade, da droga), pelos constantes deslocamentos internos dos moradores pelo bairro, pelos gestos que reverberam de um corpo a outro, e pela montagem que concatena as figuras e as moradias, recriando a geografia da favela como espaço dos interpostos, mundo do comum (ARENDT, 2009) ${ }^{10}$. Dada a destruição iminente do território físico, as Fontainhas parecem existir como eventualidade (MASSEY, 2008) ${ }^{11}$, um universo de partilha existente

10 Para Arendt (2009), trata-se não um espaço limitado, mas o artefato, o produto das mãos humanas, o que deriva dos negócios realizados entre um conjunto de pessoas, o mundo feito pelo homem. A autora usa como metáfora para este segundo traço a mesa: "Conviver no mundo significa essencialmente ter um mundo de coisas interposto entre os que nele habitam em comum, como uma mesa se interpõe entre os que se assentam ao seu redor" (p. 62). Como um intermediário, ela separa e promove a relação entre os homens. A perda da força e da conexão que mantém os indivíduos juntos é sinalizada pela autora, em oposição, pelo desaparecimento da mesa, o que mantém as pessoas sentadas umas em frentes às outras: já não estão separadas, mas tampouco possuem uma relação tangível entre si.

11 Em sua definição, Massey (2008) reforça tanto a dimensão de evento/acontecimento como de contingência, devir, que impregna um lugar, exigindo das pessoas que o habitam a ética e responsabilidade para fazer face a situações que não tem precedentes. Nesse sentido, o lugar seria destituído de regras peremptórias. A comunidade ou a identidade coletiva não seriam preconcebidas, mas resultantes de uma constante negociação entre os seres em busca do viver junto. 
entre os corpos, na constante negociação entre os indivíduos a fim de poderem viver juntos. No caso de Costa, essa dimensão existe pela rede de encontros e travessias descritas, tecendo os laços comunitários para além do espaço físico. Por um lado, impede-se o cerceamento, o isolamento da figura humana. Por outro, é favorecida a comunicação do privado com o público, a extensão do eu ao outro, e especialmente o arranjo dos diferentes em torno do comum.

\section{Considerações finais}

O que nos revelam os modos de representar o corpo humano em certo cinema da passagem do século XX para o XXı? Como os seus filmes enformam a figura ou lhe conferem presença no âmbito da imagem cinematográfica? A partir de um conjunto de obras europeias marcadamente heterogêneas, procuramos expor como o corpo é constituído ao se projetar em direção ao seu avesso, na lida com sua exterioridade. Em vez de um movimento egocêntrico, de um voltar-se para si, os personagens são representados sob natureza transitiva, relacional, subordinando-se ao contato com o outro. A procura e a consolidação dos laços afetivos/sociais definem a presença, mais do que qualquer projeto individual que poderia mobilizar os personagens e compor a fábula. Isso não implica em atribuir uniformemente aos filmes uma relação de horizontalidade entre os seres e tampouco um princípio de alteridade - pelo menos no sentido de uma ética de responsabilidade, da acolhida e da obrigação do eu para com outrem (LÉVINAS, 1994). ${ }^{12}$ Trata-se, antes, da suscetibilidade em face do diferente. Assim, Sombra, O fantasma, Ossos, No quarto da Vanda e Juventude em Marcha estruturam-se na forma de pequenas jornadas entre os corpos, fazendo da mediação com o outro o télos da figura humana.

A dinâmica relacional é conformada sob as especificidades de cada obra. Em Sombra, a projeção do eu em direção ao outro acontece pela tentativa de constrangimento, de objetificação, e no limite de elisão, da figura

12 A remissão almeja exemplificar uma compreensão, entre outras, de alteridade. Sem sentido unívoco na filosofia, 0 termo é matizado em conformidade com o horizonte epistemológico de cada autor. No caso de Lévinas (1994, 2014), está associado a uma perspectiva humanista, a uma compreensão da filosofia como sabedoria ético-religiosa surgida da relação entre o eu e o outro. Para o autor, a alteridade inclui, no face a face entre sujeitos, que o eu abandone a existência anônima e impessoal para se implicar diretamente, sujeitar-se diante do outro. 0 eu é posto na condição de refém, sem a possibilidade de escolha, de esquivar-se da preocupação e da responsabilidade para com o outro. Essa relação contém certa passividade, um "padecer", e acontece de modo assimétrico, sem a exigência de reciprocidade entre os dois lados. Conforme aponta Poirié (2007), o genocídio judeu na Segunda Guerra Mundial, com o ser humano desprovido de valor, reduzido a nada, foi determinante, como antítese, para a formulação levinasiana de uma subjetividade privada de soberania, e segundo a qual a responsabilidade para com o outro vem antes de qualquer liberdade ou essência do Sujeito. 
feminina. Impera a lógica unidirecional, impositiva: a constituição do si acontece pela anulação da subjetividade e da presença do outro. Sem consenso afetivo, a única integração entre os seres acontece pela diluição das formas masculinas e femininas no espaço pictórico preto. Já em O Fantasma, a relação é inversa: em face do outro, o protagonista redefine a sua corporeidade, reorienta sua capacidade sensorial, recria o espaço, tendo em vista sempre a tentativa de recuperar a presença vestigial do ser amado. A abertura ao diferente redunda numa transformação do si, incapaz de manter-se estável mediante a exposição ao outro. Sem efetiva relação entre os personagens, o espaço evidencia a constante busca pelo alvo do desejo. Por fim, nos filmes da Trilogia das Fontainhas, pelas redes de fraternidade entre os moradores do bairro, o aspecto relacional evolui para um cuidado ético diante do outro, uma política de resistência em meio às agruras do cotidiano. Os espaços arquitetônico e fílmico pavimentam os cruzamentos, os vasos comunicantes, efetivando as vidas partilhadas.

A fratura, a busca e a efetiva relação entre o eu e o outro demonstram um programa comum pautado na exposição mútua, nas condições de mediação, e sobretudo no princípio relacional como matriz de figuração do corpo e do espaço nas obras discutidas. Resguardadas as singularidades, a proposta de uma dimensão supra-individual acontece dentro de um paradigma anti-imunitário (ESPOSITO, 2000), sem poupar os sujeitos dos eventuais efeitos nocivos do outro. Junto a esse traço, é importante demarcar a renúncia dos filmes às grandes narrativas e a enquadramentos deterministas que poderiam reduzir os corpos e os sujeitos em cena a meros reflexos das macroestruturas socioculturais - embora os efeitos destas, como não poderiam deixar de ser, permaneçam sub-repticiamente, mormente na obra de Costa. Investe-se, em contrapartida, no universo da micropolítica, nas experiências dos corpos a partir do desejo e de regimes de partilha que potencializam a figura humana em práticas cotidianas, esboçando como finalidade última as formas de convívio. Talvez os cineastas analisados, como outros contemporâneos, proponham retroceder ao nível mais elementar de encontro entre os diferentes para só depois, quem sabe, voltar a se endereçar às visadas históricas e políticas mais amplas.

Por fim, esperamos ter demonstrado a validade de um método que destaca e investiga o sentido de um elemento fílmico a partir, prioritariamente, da superfície da imagem, de suas propriedades plásticas. Relegando ao segundo plano o drama ou a trama como dito no início do texto, tornados rarefeitos nas obras -, detivemo-nos nas dinâmicas visuais, nas correspondências dos filmes com um repertório iconográfico, 
no tratamento e na repetição dos motivos estruturantes, e na performance gestual. Por meio desses critérios, foi possível identificar a recorrência de uma circularidade derivada da expansão da figura humana, do esboroamento de seus limites visuais e corporais, mas também de sua atuação enquanto sujeito social. Cada uma das obras analisadas reivindica um espaço (da imagem, do mundo figurado, do filme) capaz de acolher o alargamento derivado da procura de um corpo por outro. Convém, num exame futuro, discutir essa condição em consonância com os respectivos projetos poéticos dos três realizadores: as potencialidades sensoriais da estética cinematográfica em Grandrieux, as transformações dos corpos gays e trans em Rodrigues, e a sombra da herança colonial na vida dos imigrantes caboverdianos filmados por Costa.

\section{Referências}

ARENDT, Hannah. A condição humana. Rio de Janeiro: Forense Universitária, 2009.

AUERBACH, Erich. Figuras. São Paulo: Editora Ática, 1997.

AUMONT, Jacques. A quoi pensent les films? Paris: Nouvelles Éditions Séguier, 1996.

De l'esthétique au présent. Bruxelas: De Boeck, 1998.

Le montreur d'ombre: essai sur le cinéma. Paris: J.VRIN, 2012.
L'oeil interminable: cinéma et

peinture. Toulouse: Séguier, 1989.

Matière d'images, redux. Paris: Les Essais, 2009.

BALÁZS, Béla. El hombre visible, o la cultura del cine. Buenos Aires: El cuenco de plata, 2014.

BALTAR, Mariana. Feminismos em tensão: da pedagogia sociocultural a uma pedagogia dos desejos. In: MURARI, Lucas; NAGIME, Mateus. New Queer Cinema: cinema, sexualidade e política. São Paulo: Caixa Econômica, 2015.

Tessituras do excesso: notas iniciais sobre o conceito e suas implicações tomando por base um Procedimento operacional padrão. Significação, Ano 39, n. 38, p. 124146, 2012.

BANU, Georges. Nocturnes: peindre la nuit, jouer dans le noir. Cahors: Biro, 2005.

BARTHES, Roland. L'effet de réel.

Communication, v. 11, p. 84-89, 1968.

BELTING, Hans. Pour une anthropologie des images. Paris: Gallimard, 2004.

BORDWELL. David. Estudos de cinema hoje e as vicissitudes da grande teoria. In: RAMOS, Fernão Pessoa. (Org.) Teoria contemporânea do cinema. São Paulo: Editora SENAC, 2005. (v. 1).

BRENEZ, Nicole. De la figure en général et du corps en particulier: l'invention figurative au cinéma. Bruxelas: De Boeck Université, 1998.

BUTLER, Judith. Ces corps qui comptent: de la matérialité et des limites discursives du “sexe". Paris: Amsterdam, 2009. 
COMOLLI, Jean-Louis. Sob o risco do real. In: GUIMARÃES, César (Org.). Ver e poder: a inocência perdida: cinema, televisão, ficção, documentário. Belo Horizonte: UFMG, 2008. p. 168-178.

COSTA, Pedro. Uma porta fechada que nos deixa a imaginar. In: MARIA, Carla; DUARTE, Daniel Ribeiro; MOURÃO, Patrícia (Org.). 0 cinema de Pedro Costa. São Paulo: CCBB, 2010. p. 147-167.

DUBOIS, Philippe. La question des Figures à travers les champs du savoir: Le savoir de la lexicologie: note sur Figura d'Erich Auerbach. In : AUBRAL, François; CHATEAU, Dominique (Org.). Figure, figural. Paris: L'Harmattan, 1999. p. 11-24.

La tempête et la matière-temps, ou le sublime et le figural dans l'oeuvre de Jean Epstein. In: AUMONT, Jacques (Org.). Jean Epstein: cinéaste, poète, philosophe. Paris: Éditions de la Cinémathèque Française, 1998. p. 267-324.

ELCOTT, Noam M. Artificial Darkness: An Obscure History of Modern Art and Media.

Chicago: The University of Chicago Press, 2016.

ELSAESSER, Thomas. Cinema mundial: realismo, evidência, presença. In: MELLO, Cecília (Org). Realismo fantasmagórico. São Paulo: Pró-Reitoria de Cultura e Extensão Universitária, 2015. p. 37-59.

ESPOSITO, Roberto. Communitas.

Paris: Essais du Collège international de philosophie, 2000.

FRONTISI-DUCROUX, Françoise. Du masque au visage : Aspects de l'identité en Grèce ancienne. Paris: Flammarion, 2012.
GARB, Tamar. Bodies of modernity. Londres: Thames and Hudson, 1998.

GUIMARÃES, Pedro. Ator como forma fílmica: metodologia dos estudos atorais.

Aniki: Revista Portuguesa da Imagem em

Movimento, v. 6, p. 81-92, 2019.

LEUTRAT, Jean-Louis: Vie des fantômes: le fantastique au cinéma. Paris: Cahiers du

Cinéma, L’Étoile, 1995.

LÉVINAS, Emmanuel. Humanisme de l'autre homme. Paris: Livre de Poche, 2014.

Totalité et infini. Essai sur

l'extériorité. Paris: Livre de Poche, 1994.

MASSEY, Doreen. Pelo espaço: uma nova política da espacialidade. Rio de Janeiro: Bertrant Brasil, 2008 .

MARTIN, Adrian. Last Day Every Day. Nova York: Punctum Books, 2012.

MILNER, Max. L'envers du visible: essai sur l'ombre. Paris: Éditions du seuil, 2005.

NOCHLIN, Linda. Realism. Nova York: Penguin Books, 1984.

POIRIÉ, François. Emmanuel Lévinas: ensaios e entrevistas. São Paulo: Perspectiva, 2007.

ROHMER, Éric. L'organisation de l'espace dans le Faust de Murnau. Quétigny: Petite bibliothèque des Cahiers du Cinéma, 2000.

SEIJA-VERGEZ, Sarah (Org.). La peau: un continent à explorer. Paris: Éditions Autrement, 2005.

SPELMAN, Elizabeth V. Woman s Body: Ancient and Contemporary Views. Feminist Studies, v. 8, n. 1, p. 109-131, 1982. 
STOICHITA, Victor I. Breve história da

sombra. Lisboa: KKYM, 2016.

VANCHERI, Luc. Les pensées figurales de

l'image. Paris: Armand Colin, 2011.

\section{Filmografia}

Juventude em marcha. Pedro Costa. Portugal, 2006. 35 mm (154 min.), som, cor.

No quarto da Vanda. Pedro Costa. Portugal, 2000. $35 \mathrm{mim}$ (178 min.), som, cor.

O fantasma. Realização: João Pedro Rodrigues. Portugal, $2000.35 \mathrm{~mm}$ (90 min.), som, cor.

Ossos. Realização: Pedro Costa. Portugal, 1997. $35 \mathrm{~min}$ (94 min.), som, cor.

Sombra. Realização: Philippe Grandrieux.

França, 1998. $35 \mathrm{~mm}$ (112 min.), som, cor. Título original: Sombre.

\section{Informações sobre 0 artigo}

Resultado de projeto de pesquisa: 0 artigo é resultado da tese de doutorado A figura humana no cinema: matéria, desejo e comunidade, defendida junto ao Programa de Pós-Graduação em Meios e Processos Audiovisuais da ECA-USP, em 2018, com orientação de Cristian Borges.

Fontes de financiamento: Bolsa de doutorado da Fundação de Amparo à Pesquisa do Estado de São Paulo (FAPESP:

2014/09365-4) e Bolsa Estágio de Pesquisa no Exterior (BEPE-FAPESP: 2016/06820-8).

Considerações éticas: Não se aplica.

Declaração de conflito de interesses: Não se aplica.

Apresentação anterior: Não se aplica.

Agradecimentos: Não se aplica. 


\section{Figures of the body and spaces of the other in cinema}

\begin{abstract}
:
The article discusses the representation of the body in films by Philippe Grandrieux, João Pedro Rodrigues and Pedro Costa made at the turn of the 1990 s to the 2000 s. From the analysis of visual dynamics and gestural performance, it shows the existence of a common program based on the primacy of affective/social practices over individual nature. In this sense, the presence of the human figure is conditioned by a relational principle: mediation between the self and the other determines the plastic aspects and bodily sensoriality, at the same time as it implies the production of spaces capable of accommodating modes of conviviality guided by desire and sharing practices.
\end{abstract}

\section{Keywords:}

Human figure. Contemporary European

cinema. Film aesthetic. Space. Exteriority.

\section{Figuras del cuerpo y espacios del otro en el cine}

\section{Resúmen:}

El artículo analiza la representación del cuerpo en películas de Philippe Grandrieux, João Pedro Rodrigues y Pedro Costa realizadas a fines de los años 90 y 2000 . Desde el análisis de la dinámica visual y el rendimiento gestual, la existencia de un programa común basado en la primacía de las prácticas afectivas / sociales sobre la naturaleza individual. En este sentido, la presencia de la figura humana está condicionada a un principio relacional: la mediación entre el yo y el otro determina los aspectos plásticos y la sensorialidad corporal, al mismo tiempo que implica la producción de espacios capaces de acoger formas de vida orientadas por el deseo y la colectividad.

Palabras clave:

Figura humana. Cine europeo contemporáneo. Estética del cine. Espacio. Exterioridad.

\section{Edson Pereira da Costa Júnior}

Doutor em Meios e Processos Audiovisuais pela Escola de Comunicações e Artes da Universidade de São Paulo, com bolsa FAPESP e passagem pela Université Sorbonne Nouvelle - Paris 3. Pós-doutorando pelo Departamento de Artes Plásticas da Escola de Comunicações e Artes da Universidade de São Paulo, com bolsa PNPD/CAPES. Universidade São Paulo, São Paulo, São Paulo, Brasil. E-mail: jredsoncosta@gmail.com 